\title{
Three-Dimensional, Nondestructive Imaging of Low Density Materials
}

\author{
J.H. Kinney, D.L. Haupt, J.D. LeMay \\ This article was submitted to \\ Materials Research Society, Boston, MA, December 1, 1999
}

\section{October 29, 1999}

U.S. Department of Energy

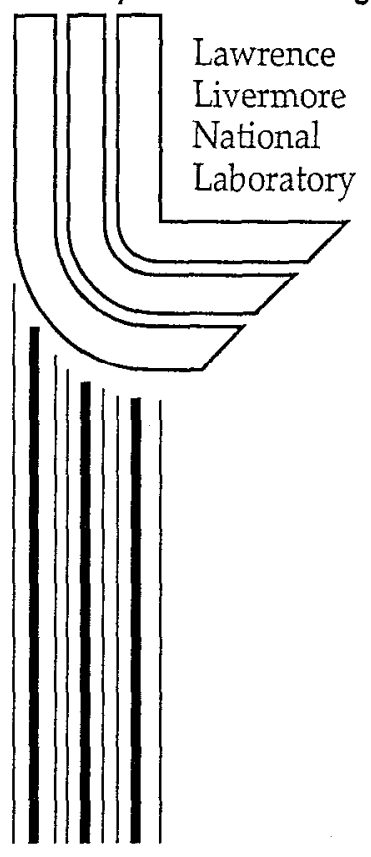




\section{DISCLAIMER}

This document was prepared as an account of work sponsored by an agency of the United States Government. Neither the United States Government nor the University of California nor any of their employees, makes any warranty, express or implied, or assumes any legal liability or responsibility for the accuracy, completeness, or usefulness of any information, apparatus, product, or process

disclosed, or represents that its use would not infringe privately owned rights. Reference herein to any specific commercial product, process, or service by trade name, trademark, manufacturer, or otherwise, does not necessarily constitute or imply its endorsement, recommendation, or favoring by the United States Government or the University of California. The views and opinions of authors expressed herein do not necessarily state or reflect those of the United States Government or the University of California, and shall not be used for advertising or product endorsement purposes. 


\title{
THREE-DIMENSIONAL, NONDESTRUCTIVE IMAGING OF LOW DENSITY MATERIALS
}

\author{
J.H. KINNEY, D.L. HAUPT, J.D. LEMAY \\ Lawrence Livermore National Laboratory, Livermore CA 94551, kinney3@llnl.gov
}

\begin{abstract}
The goal of this study was to develop a three-dimensional imaging method for studies of deformation in low-density materials during loading, and to implement finite element solutions of the elastic equations based on the images. Specimens of silica-reinforced polysiloxane foam pads, $15 \mathrm{~mm}$ in diameter by $1 \mathrm{~mm}$ thick, were used for this study. The nominal pore density was $50 \%$, and the pores approximated interconnected spheres. The specimens were imaged with microtomography at $\sim 16 \mu \mathrm{m}$ resolution. A rotating stage with micrometer driven compression allowed imaging of the foams during deformation with precise registration of the images. A finite element mesh, generated from the image voxels, was used to calculate the mechanical properties of the structure, and the results were compared with conventional mechanical testing. The foam exhibited significant nonlinear behavior with compressive loading. The finite-element calculations from the images, which were in excellent agreement with experimental data, suggested that nonlinear behavior in the load displacement curves arises from buckling of the cell walls during compression and not from any nonlinear properties of the base elastomer. High-resolution microtomography, coupled with efficient finite-element modeling, shows promise for improving our understanding of the deformation behavior of cellular materials.
\end{abstract}

\section{INTRODUCTION}

Low-density cellular structures have applications ranging from aerospace to sporting goods. In nature, cellular structures are ubiquitous. Accordingly, their small strain elastic behavior has been extensively studied. For highly idealized foam architectures, the low density limiting behavior of the Young's modulus scales as either $\rho / \rho_{m}$ or $\left(\rho / \rho_{m}\right)^{2}$ depending on whether the foam has closed-or open-celled porosity, respectively $[1,2,3]$. The quadratic dependence of the modulus with density in open-celled foams is a result of bending and torsional modes of deformation; whereas, the closed-cell foams resist deformation by direct compression. These pronounced effects of microstructure on scaling behavior potentially provide great flexibility in tailoring foams for optimal strength and stiffness in structural applications.

Large deformation behavior is far more complicated than the initial linear elastic response. Typical stress strain behavior of a foam can be highly nonlinear, even when the base material behaves linearly. Stress strain behavior of the 50\% dense elastomer foam used in this study is shown in Figure 1. The load displacement curve can be divided into three distinct regions: 1) an initially linear region, 2) a plateau region caused by the buckling of cell walls and the initial collapse of the pore structures, and 3) a region distinguished by a rapid increase in 
resistance to continued deformation as the contribution from pore collapse diminishes and the bulk modulus becomes important. This latter region is sometimes referred to as lock-up.

We report the results of an imaging study of polysiloxane elastomer foam during quasi-static compressive loading. A complete cycle of loading/unloading was recorded, with particular attention focussed on the pore morphology in the plateau region and the nascent stages of lock-up. The images were meshed for finite-element analysis, and the results were compared with the experimental stress/strain behavior.

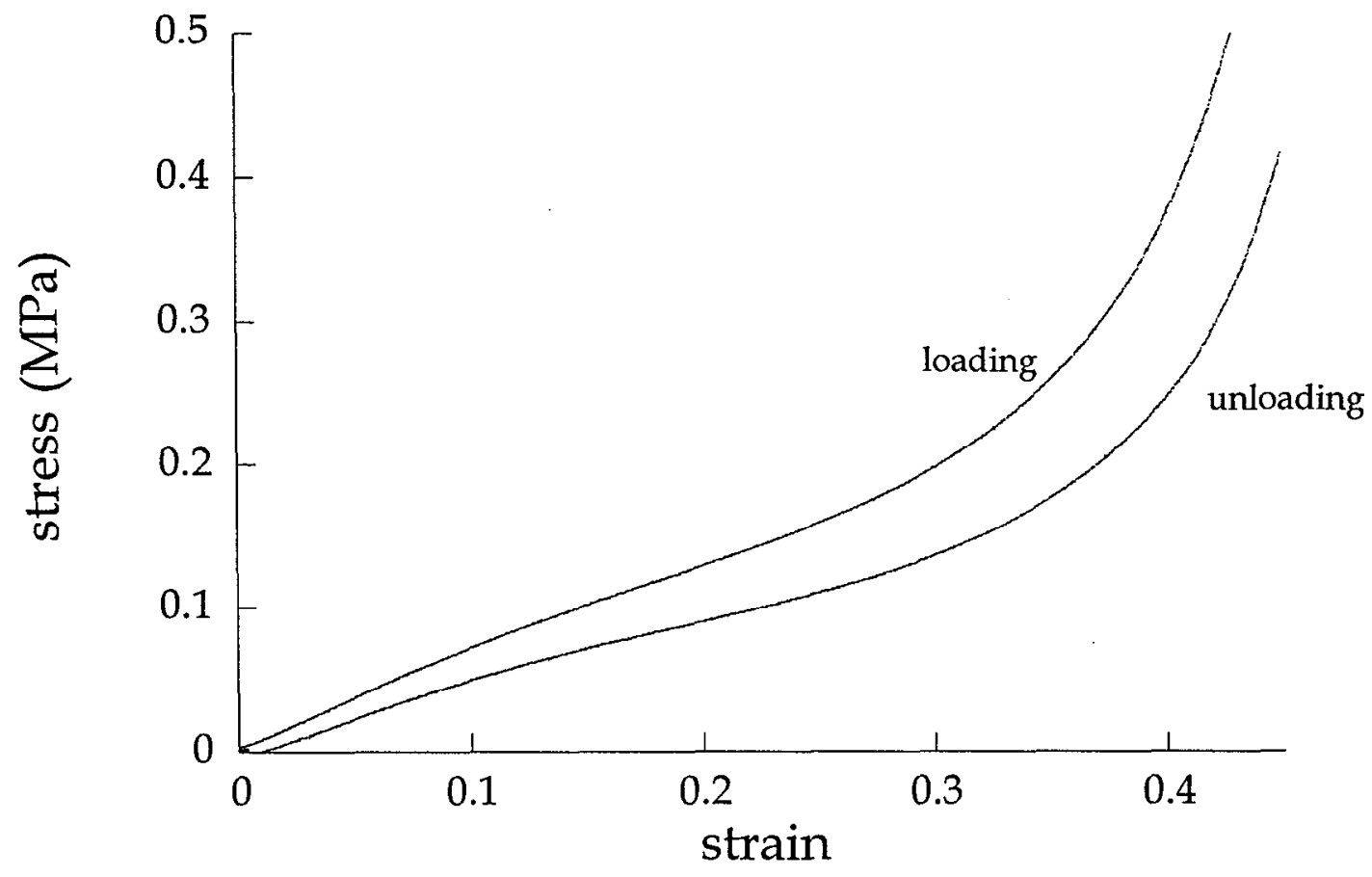

Figure 1: Experimental stress strain behavior for the $50 \%$ dense polysiloxane foam pads examined in this study. There were three distinct responses:1) an initial linear phase to about 0.07 strain, 2) a plateau region that extends to a strain of about 0.3 , and 3 ) a region of rapid rise in resistance to further deformation.

Table 1: Material constants for the two foam materials examined in this study. The apparent density $\left(\rho_{\mathrm{a}}\right)$ and cell wall $(\tau)$ thickness were determined by 3D tomographic imaging. The Young's modulus and Poisson's ratio of the base elastomer were determined from mechanical testing.

\begin{tabular}{c|c|c|c|c} 
Specimen & $\rho_{\mathrm{a}}(\boldsymbol{\%}$ solid $)$ & $\tau(\boldsymbol{\mu m})$ & $\mathbf{E}_{\mathrm{m}}(\mathbf{M P a})$ & $v$ \\
\hline $\mathbf{9 7 5 0}$ & 49.7 & 106 & 1.9 & .49 \\
\hline $\mathbf{9 7 6 0}$ & 40.6 & 77 & 1.9 & .49
\end{tabular}




\section{EXPERIMENTAL METHODS}

Commercially available elastomer foam was used for this study. The base material was a peroxide cured polysiloxane in which $\sim 25 \mathrm{wt}$. \% fumed-type silica fillers were incorporated for reinforcement. The elastic properties of the base elastomer are listed in Table 1. Porosity of the foam was controlled by the use of a sacrificial pore former $(\sim 0.5 \mathrm{~mm}$ diameter spherical urea beads). Cylindrical specimens, $15 \mathrm{~mm}$ in diameter, were prepared from $1 \mathrm{~mm}$-thick foam pads with two initial densities: $40 \%$ and $50 \%$.

The specimens were placed in a displacement controlled load frame and imaged with monochromatic synchrotron radiation. Repeated images were acquired as the specimens were uniaxially compressed in stages at $0,15,30$, and $35 \%$ strain. One complete load/unload cycle was imaged for each foam pad. The $\mathrm{x}$-ray energy was $25 \mathrm{keV}$, and the rotational increment of the tomographic scanner was 0.5 degree.

The load stage developed for this study is shown in Figure 2. Compressive load was transferred to the specimen by means of a micrometer. The loading micrometer had $0.002-\mathrm{mm}$ resolution and a large pitch diameter that resulted in a low helix angle and high leverage. The bottom specimen platen was driven by the rotary stage, while the upper end of the specimen rotated on miniature precision bearings housed within an upper anvil. A main thrust bearing inside the upper anvil took the entire load of the micrometer. In addition, there were two purely radial bearings that served to insure concentric rotation. The alignment of the micrometer axis with the lower rotational axis was controlled by six, ultra-fine, adjusting screws. A precision dial test indicator was used to determine coaxiality. Specimens were held between two acrylic platens that were clamped to the aluminum upper and lower anvils by three equally spaced screws.

Three-dimensional images of the deformed elastomer foams were obtained by Fourier-filtered back projection of the synchrotron data. Though the ultimate spatial resolution of the scanner is $2 \mu \mathrm{m}$ for small specimens, the large specimen diameters used in this study required the volume elements in the reconstructed images to be $16 \mu \mathrm{m}$ on edge. The time required to make a complete 3D image and increment the strain was just under 15 minutes. Imaging a complete load and recovery cycle required about two hours of synchrotron beam time.

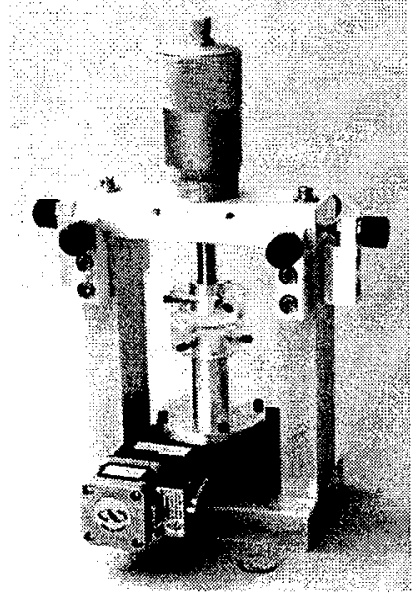

Figure 2: The micrometer driven load cell for compressing the elastomer foams while imaging. 
Mean cell wall thickness was determined by application of a well-known relationship from stereology:

$$
\langle\tau\rangle=\frac{2 V}{S}
$$

Here, $\langle\tau\rangle$ was the mean cell wall thickness, $V$ was the volume of the solid component, and $S$ was the total surface area of the foam. The surface area was determined by integration of a polygonal surface mesh and the volume was determined by voxel counting.

Finite element analyses of the images wcre performed using a voxel-based approach to meshing. Each cubic voxel of the image corresponded to a finite element. The calculations used a fixed (non-sliding) boundary condition on the load surfaces, which we believed best modeled the actual testing conditions. An isotropic linear elastic material model with $\mathrm{E}=1.9 \mathrm{MPa}$ was used for the calculations. Two values of Poisson's ratio were used: $v=0.25$ and $v=0.49$, the latter being the correct value, in order to examine bulk modulus effects on deformation behavior. Details of the model have been described elsewhere [4].

\section{RESULTS}

The measured apparent density and mean wall thickness for two foam pads are given in Table 1. A tomographic cross section through the mid-plane of the 50\% dense foam is shown in Figure 3a. The tomographic image clearly shows that all of the pores were not circular in cross section: a result of fragmenting some of the urea beads during mixing. Gradual deformation of the pore microstructure during a progression of compressive strains is shown in the vertical tomographic cross-sections of Figure 3a-d.

Large deformation of the cell walls during loading was apparent in 3-D isosurface renderings of the specimens. A 1-mm diameter cylinder, extracted from the full volume (Figure 4), shows this deformation in detail. By the first strain increment (15\%), the smallest pore throats had collapsed and sealed-off. By the time higher strains levels had been reached, large buckling and folding of the cell walls was visible.

The finite element calculations were performed on the structures at each stage of compression. Results are compared with the derivative of the experimental stress-strain curve in Figure 5. Through the plateau region, the local strains in the base elastomer remained microscopic, even though there was large deformation in the foam pad. At the beginning of lock-up, the contribution to the pad's stiffness that was attributable to the cell wall collapse diminished in magnitude, and the effects of the bulk incompressibility of the base elastomer became dominant. When the correct value of Poisson's ratio was used in the calculations, the calculated Young's modulus was noticeably higher at $35 \%$ compression than measured. If the experimental data is to be trusted, then the higher calculated stiffness may have resulted from assuming a single value for the elastic modulus (linear material model). It is possible that by $35 \%$ far-field strain some of the material members may actually have softened (nonlinear behavior at high tensile strains) or cell wall rupture might have occurred. 

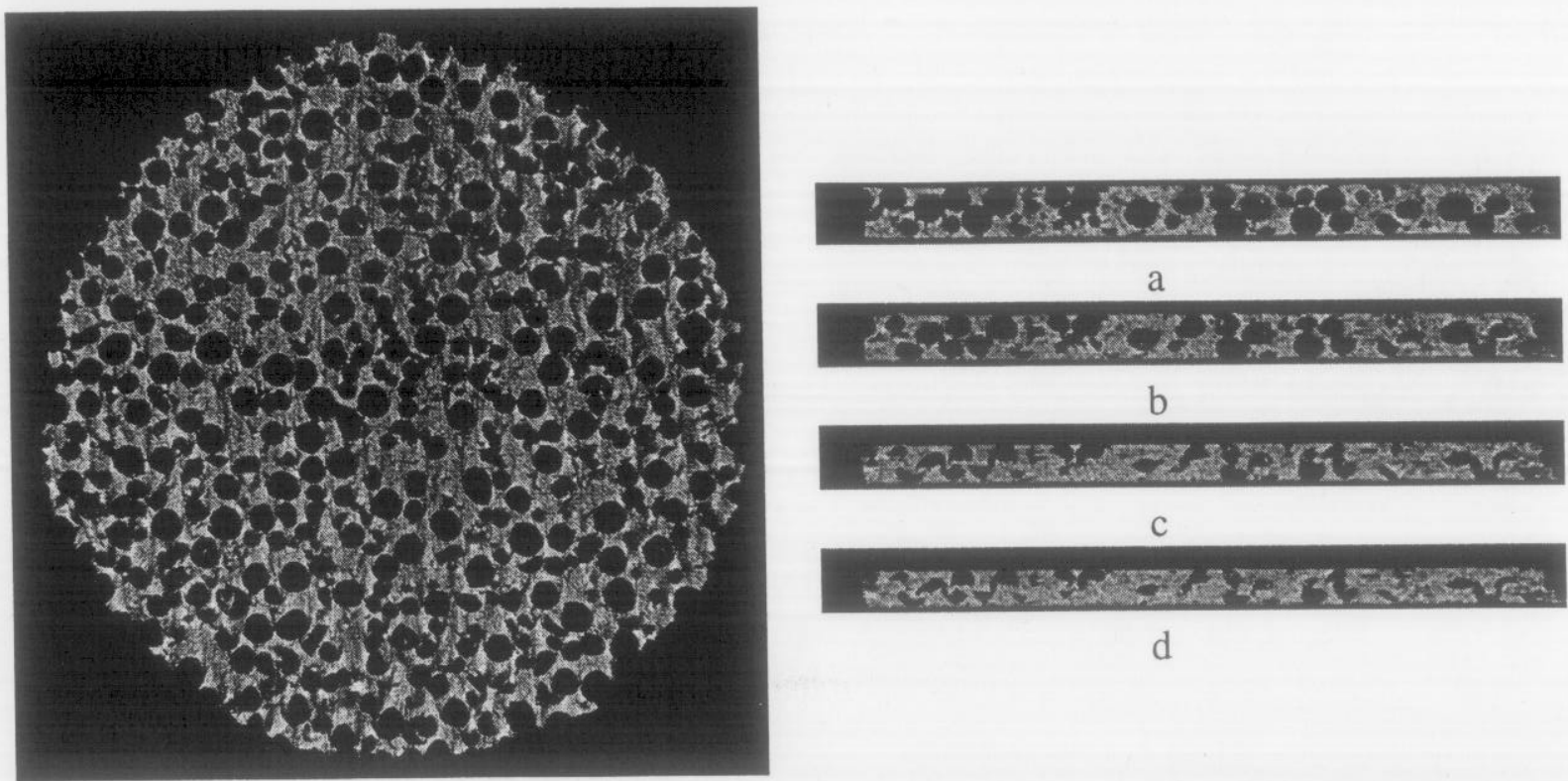

a

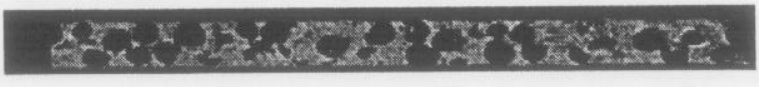

b

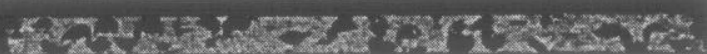

C

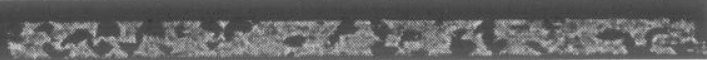

d

Figure 3: A tomograph through the midplane of an undeformed, 50\% dense foam specimen (left). Through thickness images of the foam at progressively larger strains: a) unloaded, b) $15 \%$ compression, c) $30 \%$ compression, and d) $35 \%$ compression.

\section{CONCLUSIONS}

We have demonstrated that large deformation in cellular materials can be imaged noninvasively, and that the images can be used as meshes for physically-based finite element modeling. Success required integration of a load frame with a microtomography scanner. Two approaches to load frame design for tomographic imaging had been previously proposed. The first approach, described by Breunig et al., used a radiolucent stand-off to transfer load from an actuator to the specimen [5]. With this configuration, the entire frame rotated while the standoff remained continuously in the path of the $\mathrm{x}$-ray beam.
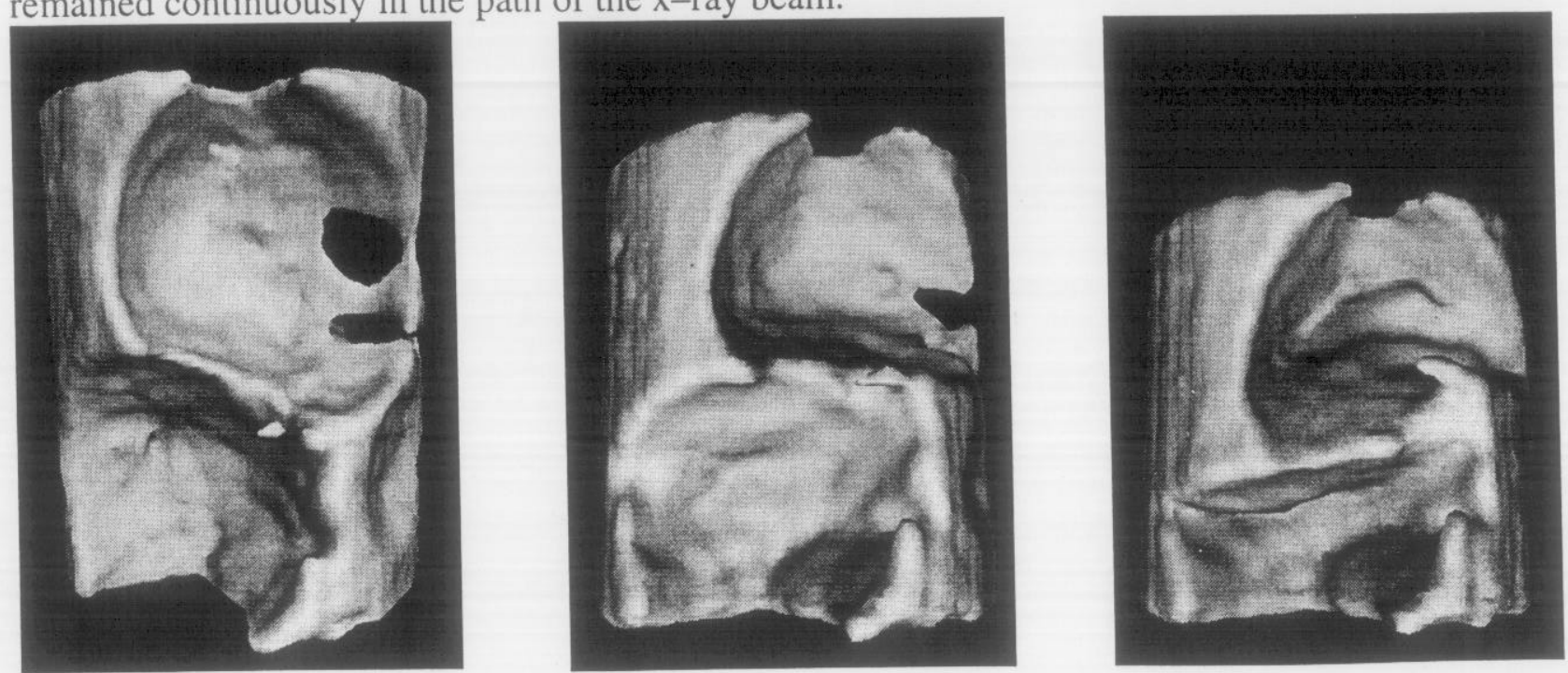
Figure 4: Isosurface renderings of a 1-mm cylinder at 0,15 , and $30 \%$ axial compression.

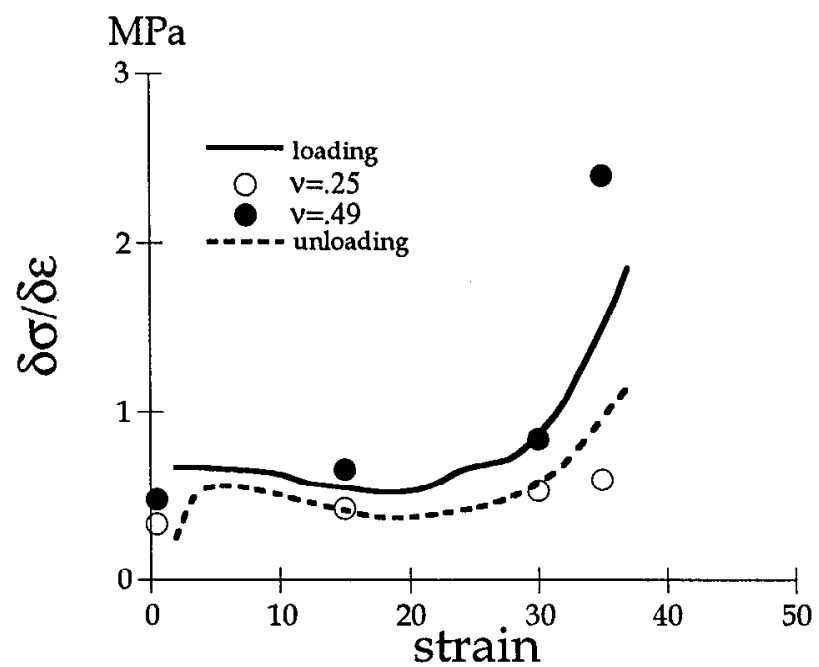

Figure 5: Differential of the stress strain data: loading cycle solid line, unloading cycle dashed line. Circles are the calculated Young's moduli at each stage of compression for Poisson's ratio of .49 (solid) and .25 (open).

The second approach, the one that we adopted here, used rotating load platens and held the frame stationary [6]. This design prevented any material other than the specimen to intersect the $\mathrm{x}$-ray beam. The use of a micrometer to dial-in fixed strains, and the use of precision bearings to allow free rotation, were the innovations in our stage design. This design removed mechanical noise that might have been present if a mechanical actuator had been used to maintain a constant displacement. The small loads required to deform the elastomer foam (less than $1 \mathrm{Mpa}$ ) made this approach feasible.

\section{ACKNOWLEDGMENTS}

We wish to thank Dr. Steve DeTeressa (Lawrence Livermore National Laboratory) for providing us with mechanical test data on the foam materials. This work has been performed under the auspices of the United States Department of Energy by Lawrence Livermore National Laboratory under contract W-7405-Eng-48.

\section{REFERENCES}

1. R.M. Christensen, Proc. Royal Soc. London A, 440,461 (1993).

2. W.E. Warren and A.M. Kraynik, J. Appl. Mech.-Trans. ASME 64,787 (1997).

3. L.J. Gibson and M.F. Ashby, Pro. R Soc. Lond. A, 382,43 (1982).

4. A.J.C. Ladd and J.H. Kinney, Physica, A240:349 (1997).

5. T.M. Breunig, S.R. Stock, and R.C. Brown, Mat. Eval., 51:596 (1993).

6. T. Hirano, K. Usami, Y. Tanaka, and C. Masuda, J. Mater. Res. 10:1995. 